\title{
Considerações sobre a apropriação do número e da linguagem numérica
}

\author{
Considerations of the number and the numerical \\ language appropriation
}

\author{
Considérations sur la propriété du nombre et de la \\ langage et numérique
}

Lidnei VENTURA

\section{RESUMO}

O presente artigo discute o número como uma forma de linguagem explicativa da realidade social contemporânea quando esta depende de informações matemáticas. Apresenta os elementos constituintes da linguagem numérica - código e sentido - e argumenta contra as concepções de número que reduzem sua compreensão aos aspectos de ordem e quantidade. Afirma que tais reducionismos limitam as possibilidades de apropriação das relações humanas quando o sentido atribuído ao número extrapola sua condição ordinal e cardinal e exprime aspectos convencionados. A hipótese central do artigo consiste em considerar o código numérico e o sentido atribuído a ele como elementos reflexivos, interdependentes, que só podem ser compreendidos levando-se em conta a função social dessa forma de linguagem e os câmbios sociais que pressupõem o uso de tal ferramenta conceitual.

Palavras-chave: matemática, número, linguagem numérica, código, sentido.

\begin{abstract}
This article discusses the number as a form of language explaining the contemporary social reality in which this information depends on mathematics. It presents the components of the numerical language- code and sense- and argues against the number of designs that reduce their understanding the points of order and quantity. It states that such reductionism limits the scope of ownership of human relations when the meaning attributed to the number extrapolates his ordinal and cardinal
\end{abstract}


condition and expresses conventional aspects. The central hypothesis of this article is to consider the numerical code and the meaning assigned to it as reflective elements, interdependent, which can only be understood taking into account the social function of this language form and social exchange which require this tool conceptual use.

Index terms: mathematics, number, numerical language, code, sense.

\section{RÉSUMÉ}

Cet article examine le nombre comme une forme de la langue pour expliquer la réalité sociale contemporaine dans laquelle cette information dépend de les mathématiques. Il présente les éléments du langage numérique- le code et la direction- et il est contre des conceptions du nombre qui réduisent leur compréhension aux aspects de l'ordre et de la quantité. Il précise que ces réductions limitent les possibilités de les relations humaines lorsque le sens attribué au nombre extrapole sa condition ordinal et cardinal et exprime les aspects convenus. L'hypothèse centrale de cet article est d'examiner le code numérique et le sens qui lui est assigné comme des éléments de réflexion, interdépendants, qui peuvent être compris en tenant compte de la fonction sociale de cette forme de langage et des échanges sociales qui exigent l'utilisation de cet outil conceptuel.

Mots clés: mathématiques, du nombre, de la langue numérique, le code et la direction.

\section{Introdução}

O presente artigo foi produzido a partir de pesquisa realizada no Mestrado em Educação e Cultura da Universidade do Estado de Santa Catarina, à luz do capítulo terceiro da dissertação, intitulado "O número numa perspectiva histórica”, que foi defendida e aprovada no ano de $1999^{1}$. Desde lá, vimos defendendo que o ensino do número, sobretudo no âmbito

\footnotetext{
${ }^{1}$ Nos capítulos primeiros da referida dissertação apresentamos os princípios de fundamentação teórica que dão sustentação a uma abordagem histórica do número, apoiando-se, sobretudo, numa concepção de linguagem extraída da abordagem marxiana como está posta nos Manuscritos Econômicos e Filosóficos (1844), em A Ideologia Alemã (1845) e O Capital (1867), que enfatizam o caráter intrinsecamente social do homem e de sua autoprodução, pressupostos esses que seriam posteriormente adotados e desenvolvidos, no âmbito da psicologia, por Lev Vygotsky e Henri Wallon.
} 
do ensino fundamental, seja concebido como uma complexa forma de linguagem da qual as pessoas precisam urgentemente se apropriar, haja vista o fato de a sociedade atual se expressar majoritariamente de forma numérica. Exemplo disso são nossos contatos diários com caixas eletrônicos, sistema monetário, gráficos e tabelas em jornais, indicadores econômicos, rótulos de produtos etc. Enfim, vivemos imersos num mundo de informações numéricas que precisamos compreender, processar e operar para não sermos excluídos de importantes câmbios sociais do mundo contemporâneo.

O objetivo principal do artigo é argumentar quanto à necessidade de superação da concepção reducionista vigente acerca do número, atribuindolhe tão somente propriedades de quantificação e seriação, o que do nosso ponto de vista não dá conta de toda complexidade da linguagem numérica e da sua função social. Para tanto, desenvolvemos um estudo sobre os elementos que compõem a linguagem numérica e sua importância na socialização da ciência Matemática, ainda vilã quando se fala de indicadores educacionais e sucesso escolar no ensino fundamental e médio.

\section{Pressupostos da linguagem numérica}

Como toda forma de linguagem, a numérica responde às necessidades que os homens foram criando ao longo de seu desenvolvimento histórico, enquanto produziam sua vida. Permitindo aos homens expressarem matematicamente a sua realidade social, a linguagem numérica se compõe de um determinado código ou signo e de um significado ou idéia a ser veiculada por meio deste código. Estes elementos de modo algum se separam ou se opõem, ao contrário, o nome do número e o que ele representa são como que reflexivos ${ }^{2}$, já que não há utilização do

\footnotetext{
2 Optamos pelo uso do termo "reflexividade" por melhor expressar, cremos, a interdependência entre signo e significado, em se tratando do número. Marx exemplifica em bem a reflexividade entre dois conceitos, dizendo: $E^{\prime}$
} 
número em que o signo numérico não expresse determinado conteúdo dado pelas relações sociais que envolvam elementos matemáticos. Dado o caráter convencional da linguagem numérica, determinado pelos homens conforme as necessidades intrínsecas a cada tempo, a relação entre código e sentido não é arbitrada pelos interlocutores, ela é regrada, ordenada por um sistema de numeração, que no hindu-arábico, é decimal. Isto quer dizer que não utilizamos o código numérico de qualquer jeito, a nosso bel prazer, mas sob o imperativo de uma lógica: o sistema de numeração, que nos obriga a respeitar uma dada forma de ordenar os números.

Os elementos que compõem a linguagem numérica, o código e o sentido, encontram-se reunidos, articulados na prática social, que, na verdade, é a própria razão de ser desta forma de linguagem. E é desta prática que resulta a utilização da linguagem numérica para as mais variadas finalidades de comunicação que dependam de recursos matemáticos.

Somente encarado como sendo uma forma de linguagem é que pode o número expressar o dinamismo das relações sociais contemporâneas. No entanto, é comum se atribuir ao número um prévio caráter ambivalente de quantidade e série. Isto decorre de uma compreensão parcial do uso social da linguagem numérica, reduzindo-se a sua aplicação. É claro que se o número for analisado em si mesmo, como numa explicação escolar, destituído de seu elemento histórico, há uma divisão formal do número em cardinais e ordinais. Entretanto, o exercício social da linguagem numérica organiza o código de modo a extrapolar esta formalidade e isto se dá por uma exigência do próprio conteúdo das relações sociais determinantes do uso do número.

Tentaremos exemplificar o quanto a estruturação do código numérico, no seu uso social, extrapola os aspectos cardinais e ordinais do número.

curioso o que sucede com essas conceituações reflexas. Um homem, por exemplo, é rei porque outros com ele se comportam como súditos. Esses outros acreditam que são súditos, porque ele é rei. (MARX, 1985, p.66) 
Num jogo de cartas, os números podem representar ordem e quantidade ou, dependendo dos jogadores e do tipo do jogo, podem ser ao mesmo tempo uma coisa e outra, assim como nenhuma das duas, já que a convenção do jogo estrutura o código de maneira a comunicar somente arbitrariedades, tais como o número de determinada carta virar coringa, tornando-se, assim, qualquer outro número. Nesta relação, o ÁS pode equivaler ao número UM, vinte um ou simultaneamente, estes dois números. Já o número que acende no elevador comunica tanto a ordem do andar quanto a quantidade de andares acima do térreo em que se está; mas um número de telefone é completamente arbitrário na sua representação, pois despreza o caráter formal do número e passa a representar o nome de um assinante. Nota-se que, neste caso, o número do telefone pode representar, para a companhía telefônica, uma determinada série de assinantes, o que no uso geral dos próprios assinantes tem um caráter bem diverso. Somente o uso social é que pode explicar a função de um determinado número. Vejamos este endereço: Av. Treze de maio, 140, sala 305. Não precisamos que nos digam em que andar do prédio fica esta sala, porque o número 305 refere-se tanto à sala quanto ao terceiro andar. $\mathrm{O}$ dado, terceiro andar, ficou subentendido na estruturação arbitrária do código. Poderíamos elencar uma infinidade de usos sociais onde o número não expressa ordem ou quantidade, devido àquele caráter arbitrário, convencional da linguagem numérica, já mencionado.

Destes exemplos inferimos que sendo uma forma de linguagem, os números expressam mesmo o conteúdo de determinadas relações humanas, daí a necessidade de apropriação desta linguagem por parte dos indivíduos de modo a poderem compreender e atuar no mundo contemporâneo, no que dependa de uma leitura matemática. Isto demanda um pleno domínio do código, do sentido e do elemento de estruturação do código, isto é, a base de numeração; caso contrário, a referida leitura se torna fragmentada, ou resulta mesmo impossível. 
Como sabemos, o conceito piagetiano do número concebe este como sendo uma relação mental que o indivíduo faz entre os objetos: é um conhecimento do tipo lógico-matemático, que o indivíduo constrói pondo objetos em relação. Por sua vez, este conhecimento é uma síntese entre o conhecimento social e o conhecimento físico ou empírico. No caso do número, o conhecimento social se refere ao código ou ao nome do número (o signo) e o conhecimento empírico se refere ao significado, ou seja, a quantidade ou série correspondente ao signo. Pondo objetos em relação, segundo a teoria piagetiana, o indivíduo constrói aquilo que chama de conservação numérica. De um lado apresenta-se o primado do sujeito (relações mentais), do outro, apresenta-se o primado do objeto (físico e social). Detectamos aqui, de maneira inequívoca, as concessões de Piaget às concepções inatistas e empiristas do conhecimento. Sendo o conhecimento definido como uma adaptação e pressupondo estes dois esquemas, um de assimilação e outro de acomodação, concede-se nestes próprios esquemas, a um só tempo, ao primado do sujeito e do objeto. Cremos que, antes de superar o debate, que vinha intensificando-se desde o século $\mathrm{XV}$, entre inatismo e empirismo, o que Piaget faz é conciliar os dois primados, sujeito e ambiente, a princípio opostos, agregando-os sob o nome de adaptação. Assim ele esclarece, do ponto de vista biológico, como os aprioris podem ser conciliados:

[...] a acomodação é determinada pelo objeto, enquanto que a assimilação é determinada pelo indivíduo. Então, assim como não há acomodação sem assimilação, já que é sempre a acomodação de alguma coisa que é assimilada a um esquema de conduta qualquer, de igual modo não pode haver assimilação sem acomodação denunciando que o esquema de assimilação é geral e que é preciso sempre acomodá-lo às situações particulares (BRINGUIER, 1978, p.63).

Do mosaico epistemológico, que considera o número como a síntese entre o conhecimento social e empírico, resulta o questionamento não ontológico da possibilidade de existência de conhecimento do tipo não social; outro, decorrente deste, é que ao se manipular objetos empiricamente estes não estariam configurados pela sociedade, seja na sua forma ou no seu 
conteúdo. Analisaremos estes problemas em seguida, pois a questão que nos interessa de perto, agora, é saber da possibilidade de se separar o código do significado em se tratando de linguagem numérica.

Anteriormente, admitimos que há reflexividade entre código e sentido na linguagem numérica, já que na prática social nos servimos do código para expressar ou interpretar de forma matemática determinada mensagem. Para que isso ocorra, há que se pressupor o domínio do sistema de numeração, que estrutura e organiza a linguagem numérica, senão não pode haver sentido no uso do código. É, então, pensando e pressupondo um sentido que eu me sirvo do código para me comunicar ou me apropriar da comunicação nesta forma de linguagem. Por isso, no estudo do número, advogamos a impossibilidade de fragmentação entre código e sentido; isto é possível somente considerando-se o número em si e não materializado na forma de linguagem. Quando falamos ou escrevemos 13, nunca o fazemos sem intenção, sem que haja uma implicação semântica. A recíproca é verdadeira, pois para nos expressarmos matematicamente só podemos fazêlo levando em conta a estrutura do código numérico, aquilo que poderíamos chamar de sintaxe do número, isto é, as determinações próprias do sistema decimal para organização numérica. Mesmo se considerarmos o 13 como significando sorte ou azar (aspecto semântico), temos que respeitar o valor posicional de cada um desses números (aspecto sintático). Embora não sendo este segundo aspecto o que mais nos interessa, no momento, permanece fundamental. Esta imbricação entre código e sentido não é rígida, pelo contrário, precisa estar adequada às exigências das relações humanas que envolvam o uso de números. É no câmbio social, portanto, que se define qual aspecto (semântico ou sintático) será privilegiado. Por certo o médico, quando pede ao paciente que fale 33, não está preocupado com o código, mas com a sonoridade desta junção de números; a bebida de nome 51 não tem no código a sua razão, já que o número é o seu nome e poderia ser qualquer outro que o fabricante quisesse; mas o número um da cerveja é 
taxativo em dizer que o mais importante é seu lugar de primeira, dando ênfase na estruturação do código, no valor de posição. Somente no pensamento, de forma abstrata, é que podemos separar o código numérico do seu respectivo sentido. Nas situações objetivas de uso do número, que se realiza na forma de uma linguagem, o signo numérico (o código) e o sentido (a idéia) estão coarctados, são reflexivos, de modo que um não existe sem o outro na prática social.

Contrariamente à compreensão piagetiana, afirmamos que o indivíduo não se apropria unicamente do número em si, mas da linguagem numérica como um todo, extrapolando o sentido da conservação numérica, que aprisiona e cristaliza o uso social do número, indicando apenas ordem ou inclusão de classes. Decorre daí que a apropriação do número não pode residir na relação do indivíduo com o objeto ou pondo-se objetos em relação, como se fosse construção interna, muda; pelo contrário, ao se deparar com determinado objeto, o indivíduo, de antemão, já se depara com os determinantes sociais deste, configurados que estão por várias formas de linguagem e, dentre elas, a linguagem matemática. Mas para se admitir essa compreensão, é preciso encarar não somente a linguagem, mas o próprio indivíduo como produto social, como um ser que se faz somente em sociedade. A este respeito Marx elucida a relação entre indivíduo e sociedade:

Acima de tudo, é mister evitar conceber a 'sociedade' uma vez mais como uma abstração com que se defronta o indivíduo. O indivíduo é o ser social. A manifestação da sua vida - mesmo quando não surge diretamente na forma de uma manifestação de vida comunitária, realizada em cooperação com os outros homens - constitui, pois, uma expressão e uma confirmação da vida social. A vida individual e a vida genérica do homem não são diferentes, por muito que - e isto é necessário - o modo de existência da vida individual seja um modo mais específico ou mais geral da vida genérica, ou por mais que a vida genérica constitua uma vida individual mais específica ou mais geral (MARX, 1979, p.119).

Sob este prisma, passamos a considerar os próprios objetos nunca em si, mas como objetos humanizados - humanidade objetiva - e não uma 
abstração de toda sociedade. É inconcebível uma relação, por assim dizer, original, adâmica, com determinado objeto sem que o corpo social tenha-lhe configurado anteriormente o objeto e o tipo de relação a ser estabelecida. Admitir tal possibilidade significaria dizer que o indivíduo produz-se a si mesmo, isolado do conjunto social. Contrariando esta compreensão, lembremos que no Livro do Jângal, Mowgli só se humaniza em contato com os aldeões e que mesmo Robinson Crusoé, na sua ilha deserta, ao criar seus instrumentos de trabalho, artigos de fé etc., nada tem de original, mas ele os cria como um inglês do século XVII, como produto de sua época ${ }^{3}$. Nosso Robinson não é senão síntese de múltiplas relações sociais, haja vista que o caráter social é o caráter universal de todo movimento; da mesma forma que a sociedade produz o homem como homem, também ela é produzida por ele (cf. MARX, 1979, p.118).

Considerando o número como uma construção individual, como o faz Piaget, o caráter social do homem se transmuda por completo, dando lugar a uma visão humano-sincrética, cedendo lugar à espécie. O "homem em si" piagetiano só pode admitir uma relação sujeito-objeto abstrata; a um só tempo sujeito abstrato, original e objeto abstrato, incontaminado de sociedade, que deságua inevitavelmente numa certeza sensível abstraída do corpo social, desconsiderando que Mesmo os objetos da mais simples certeza sensível são-lhe apenas dados por meio do desenvolvimento social, da indústria e do intercâmbio comercial (cf. MARX, 1984, p. 27).

Sendo os objetos sínteses de relações humanas, a relação sujeitoobjeto não é imediata; é relação sujeito-sujeitos-objeto; numa palavra, minha ação não se dá sobre um mundo qualquer, mas sobre um mundoobjeto humanizado. Essa última consideração inviabiliza uma compreensão abstrata do homem, solitária, individual, pois: Quando o homem se defronta

\footnotetext{
${ }^{3}$ Robinson, ao notar que já se passara um ano na ilha deserta, jejua e agradece a Deus por estar vivo. Seria de se perguntar por que um homem perdido numa ilha deserta tenha que contar o tempo ou que construir um calendário? É que mesmo na sua profunda solidão, Robinson vive em sociedade. Como diria Marx: o homem só pode isolar-se em sociedade.
} 
consigo mesmo, também se está defrontando com outros homens. O que é verdadeiro quanto à relação do homem com o seu trabalho. Com o produto desse trabalho e consigo mesmo também o é quanto à sua relação com outros homens, como trabalho deles e com os objetos desse trabalho (cf. MARX, 1979, p.97).

Em Piaget, não só há possibilidade de construção isolada do conhecimento, como há apologia desta. Num certo momento ele advoga que o indivíduo pode criar seus símbolos independentes da sociedade, na sua relação como os objetos:

Esclareçamos ainda que, de acordo com um hábito dos lingüistas útil de acompanhar-se em psicologia, um símbolo deve definir-se como implicando um vínculo de semelhança entre o significante e o significado, ao passo que o signo é 'arbitrário' e repousa necessariamente numa convenção. $O$ signo exige, pois, a vida social para se constituir, ao passo que o símbolo já pode ser elaborado pelo indivíduo sozinho (como no brinquedo das criancinhas) (PIAGET, 1983, p.128).

Nesta passagem, quando evoca a brincadeira infantil "fazer comidinha", Piaget considera original, portanto, independente das convenções sociais, que as crianças utilizem, por exemplo, uma pedra para simbolizar uma guloseima. Vejamos mais de perto esse caso. Ora, simbolizar uma guloseima pressupõe, primeiro, uma convenção do que seja guloseima; segundo, pressupõe uma criança que goste de guloseima e que possa comê-la; terceiro, "fazer comidinha" já é em si um produto social, um produto do mundo adulto. Não é preciso ir muito além para se achar as determinações sociais do "ato simbólico" de considerar uma pedra como uma guloseima. Nesta pequena cena, nada tem origem no sujeito, nada há que já não tenha sido antes configurado para ele, pois as crianças não podem se relacionar a não ser com coisas que são, ao longo do tempo, humanizadas para elas. Não há, no mundo infantil, nem no mundo adulto, objetos, apenas. Tudo o que existe são objetos configurados pela mão do homem.

A conceituação ideal, abstrata do número, despreza o seu entendimento objetivado na forma de linguagem numérica, por meio da qual 
os homens se põem em relação uns com os outros, nomeando matematicamente os entes de sua realidade. Por desprezar o caráter social do homem, o construtivismo piagetiano é levado também a desprezar o caráter social das categorias conceituais que este produz.

Sendo o número entendido no campo da linguagem, onde a contribuição da Epistemologia Genética é vaga, pensamos ter dado a este uma conceituação que vai além do seu caráter lógico-matemático. O próprio Piaget esclarece a impossibilidade de o seu construtivismo explicar a aquisição de conhecimentos que não decorram de possíveis atividades do sujeito, de certa forma restringindo sobremaneira a aplicação deste referencial ao ensino. Assim ele admite:

Mas os problemas que persistem no caso das disciplinas propriamente literárias consistem na previsão de como conceder um lugar satisfatório, na formação atual e futura dos alunos, a estes dois componentes fundamentais da educação científica: uma 'atividade' autêntica dos alunos chamados a reconstruir e em parte reinventar as verdades que é preciso assimilar, e sobretudo uma prática individual do espírito experimental e dos métodos que o mesmo comporta. De fato não se reinventa o latim, tampouco a História, e ninguém se iria aventurar em experiências ('para ver', portanto heurísticas, ou de controle das hipóteses explicativas) sobre a civilização grega. Por outro lado, se já começamos a conhecer as fases de formação das operações lógico-matemáticas ou de causalidade na inteligência dos alunos, em suas manifestações em parte espontâneas, nós não possuímos - ou ainda não - conhecimentos equivalentes no tocante aos mecanismos constitutivos que originam as estruturas lingüísticas ou que determinam a compreensão dos fatos históricos. Do ponto de vista da pesquisa psicopedagógica, eis aí uma série de problemas ainda em aberto, comportem elas, ou não, soluções compatíveis àquelas abordadas acima (PIAGET, 1978, p.25).

Nesta passagem, segundo entendemos, Piaget admite uma diferenciação entre conhecimento lógico-matemático e os que decorrem do que chama derivados de estruturas linguísticas do indivíduo. Numa palavra: ele admite não saber como os sujeitos aprendem, ou melhor, constroem, os fatos históricos, a literatura, as artes etc., pois não há possibilidade de ação sobre estes objetos do conhecimento. Como ele mesmo afirma, não é possível experimentar "a Grécia antiga", "a Revolução Francesa" etc., daí não serem passíveis, estes conteúdos, de explicação por meio da ação 
construtiva, logo, não são passíveis de explicação pela Epistemologia Genética. A solução então apresentada para o impasse nos parece superficial (contrastando com a postura cientificista do autor), ou seja, a admissão hipotética de existência no sujeito de pseudoestruturas linguísticas. Como no âmbito das relações sociais os conhecimentos raramente derivam de possíveis ações construtivas, pensamos que tudo carece ainda de explicação, mesmo no caso do número que, sob o nosso enfoque, é deslocado para o campo da linguagem.

Por outro lado, compreendendo o número como uma forma de linguagem, vislumbramos a possibilidade de seu ensino e sua apropriação pelos alunos, pressupondo, por parte dos interlocutores envolvidos no processo de ensino e aprendizagem, competências quanto ao domínio do código - incluindo nele as regras da base de numeração decimal - e clareza quanto ao sentido ou idéia veiculada por este.

A fim de explicitar a linguagem numérica, passamos agora ao seu estudo de forma mais sistemática.

\section{Elementos que compõem a linguagem numérica}

Apesar de destacarmos aqui separadamente cada um dos elementos que compõem a linguagem numérica, isto serve apenas para uma melhor explicitação didática do assunto, pois, como dizíamos, código e sentido são reflexivos, formando as várias possibilidades de expressões numéricas da realidade humana.

A apropriação da linguagem matemática, na sua configuração atual, pressupõe não apenas o domínio do código numérico, isto é, o conhecimento dos numerais, é preciso também se conhecer o seu emprego em diversos contextos semânticos. Por outro lado, para se poder dar sentido ao uso deste código, é preciso apreensão de todos os princípios e implicações da base de numeração decimal. 
Para que consideremos alguém competente quanto ao domínio da linguagem numérica, é preciso levar em conta seu conhecimento dos dois aspectos a que nos referíamos, ou seja, o aspecto sintático (numerais e base de numeração) e o semântico (expressão matemática de uma dada realidade).

\section{O código}

Assim como a escrita alfabética é composta por um dado conjunto de signos, a escrita dos números também possui o seu código. O domínio do código alfabético, pela quantidade de signos sonoros (letras) de que dispõe (mais os diacríticos, acentuação etc.), apresenta-se, segundo nosso ponto de vista, infinitamente mais complexo do que o código numérico. Se considerarmos apenas as sílabas formadas pela junção das consoantes (com exceção do $\mathrm{H}, \mathrm{Q}, \mathrm{K}, \mathrm{Y}$ e W) às cinco vogais, isso resulta em mais ou menos 80 unidades. Já o código numérico, cremos que é extremamente mais simples ${ }^{4}$, pois se compõe de apenas dez dígitos (do latim digitus: dedos) que, articulados, originam todas as expressões numéricas existentes. É claro que há outros elementos complicadores, como as propriedades aditiva e multiplicativa do sistema decimal, o valor posicional dos números etc. Considerando-se apenas os numerais, basta uma junção simples dos dez dígitos.

Ao analisarmos o código numérico, o primeiro dado a considerar é a correspondência entre o dígito (signo) e o nome dado a ele (numeral), pois se trata de uma convenção puramente arbitrária, que varia de língua para língua. Embora possamos encontrar similaridades entre os nomes dos números mesmo em línguas de troncos diferentes, cada uma determinou para os números um nome diferente: no inglês, o dígito 5 chama-se "five",

\footnotetext{
${ }^{4}$ O Professor Bernal atesta a simplicidade do nosso código numérico: “... o aperfeiçoamento de um sistema numérico com notação de lugar e a introdução de um zero - aquilo a que hoje chamamos os números árabes, que tornaram as operações aritméticas uma coisa que qualquer criança pode aprender." (BERNAL, 1975 , p.282)
} 
em português é "cinco" e em francês é “cinq". É importante lembrar que nem sempre o nome do número corresponde à sua representação na forma do código, pois existem outras arbitrariedades. Vejamos: depois de formarmos uma dezena, ou seja, dez, o número seguinte deveria (considerando a propriedade aditiva do sistema) ser 10 e 1 (uma dezena mais uma unidade), chamando-se esse número "dezeum", assim como o seu sucessor, “dez(e)dois” etc. Nota-se que isso só acontece após o número 15, isto é, o número 10 e 6, dez(e)sseis. No entanto, convencionou-se chamá-los de onze (11), doze (12), treze (13), quatorze (14) e quinze (15). Essa "ilogicidade" também aparece na formação dos múltiplos da base de numeração. Depois do dezenove, não chamamos seu sucessor de "dezedez", mas sim duas dezenas, ou seja, vinte. Assim sucessivamente até chegar a dez dezenas, que chamamos de cem em vez de "noventaedez", ou, mais além, mil em vez de "novecentos e noventaedez". Essas arbitrariedades devem ser consideradas na representação atual do código, pois nelas está implícito o movimento desta forma de linguagem. As formas-numerais, que utilizamos hoje, nem sempre foram assim, mesmo para os numerais hinduarábicos. O zero, por exemplo, não faz muito tempo, entre os árabes, era representado por um ponto e não por um círculo pequeno e as representações gráficas dos numerais não obedeciam necessariamente à ordem atual.

Os princípios de ordenação do código numérico que usamos derivam da base de numeração decimal, de modo que para nos servirmos deste tipo de código devemos respeitar as regras de junção dos dez dígitos, ou seja, levar em conta o seu valor de posição, a ordem de inclusão, o uso do zero para representação do nada e outras. Em qualquer ocasião de uso do número subentende-se a função organizadora da base de numeração decimal. Por exemplo, os números do chassi de um carro, que parecem ser arbitrários ou talvez um número de ordem de fabricação, obedecem ao rigor do valor posicional de cada número, neste caso o valor absoluto de cada um, ainda 
que sejam apenas demarcatórios e se misturem letras a eles. O uso do número mesmo como cabalístico pressupõe sua dependência da base de numeração, como no caso do número treze (13), que independentemente de do que signifique esotericamente, só pode ser formado pela junção do um e do três (tredecim para os latinos), respeitando-se o valor posicional do um como uma dezena ou dez inclusões; o mesmo acontece com o número bíblico 666, que certamente não significa nem ordem, nem quantidade, mas com certeza, neste caso, o que importa não são os valores absolutos e sim relativos dos números seis, decorrendo daí que para se dizer que o número da besta apocalíptica é 666 (seiscentos e sessenta e seis) não há outro modo. Mesmo se este número for escrito em romano, há que se respeitar as regras daquele sistema de numeração, ficando assim: DCLXVI . Entretanto, para o registro gráfico, o sistema arábico é muito mais simples. Vejamos o ano de 1869: utilizando-se o sistema romano, teríamos MDCCCLXIX. A notação de lugar do número arábico facilita incomparavelmente este registro, reduzindo-se cinco inscrições do sistema romano, já que nele se usa para isso apenas quatro signos.

\section{Eis algumas características fundamentais do sistema decimal:}

QUANTO AOS NUMERAIS - Dez (10) dígitos para representação biunívoca da base de numeração: 1 a 9 e o zero para representação de nenhuma unidade.

VALOR DE POSIÇÃO - Atribui-se ao número um valor absoluto número em si, e um valor relativo - o valor que ocupa na classe que representa. Por exemplo, 1869: o 9 possui valor absoluto 9 e valor relativo 9 (classe: unidades); o 6 possui valor absoluto 6 e valor relativo 60 (classe: dezenas); o 8 possui valor absoluto 8 e valor relativo 800 (classe: centenas) e o 1 possui valor absoluto 1 e valor relativo 1000 (classe: unidade de milhar). 
NOME DOS NÚMEROS - Cada algarismo possui um nome. Há arbitrariedades na fala dos números quando da composição de unidades a partir da dezena.

PROPRIEDADE ADITIVA - Na sequiência numérica temos sempre a inclusão de uma unidade à anterior.

PROPRIEDADE MULTIPLICATIVA - Facilidade de se trabalhar com os múltiplos da base de numeração por inclusão do zero: Por exemplo: $10,20,100,1000 \ldots$

OPERAÇÕES ARITIMÉTICAS - Facilidade no cálculo gráfico pela operação com algoritmos.

\section{O sentido}

O uso do código numérico, assim como o de qualquer código, decorre da pressuposição de um sentido intrínseco ao uso social que fizermos do número. Além das quantificações e ordenações matemáticas do mundo, as idéias possíveis de serem veiculadas pelo número vão muito além dessas operações, como já argumentamos. Variam ao infinito, em contextos semânticos completamente diversos e sua aplicabilidade, na sociedade contemporânea, parece não ter limites. Estando subentendido a convencionalidade do código numérico, com suas normas de organização, o sentido a ser veiculado por este é determinado apenas pela relação dos interlocutores envolvidos no processo comunicativo possibilitado pelo número. Certamente dois matemáticos conversando sobre determinado teorema vão dar um sentido técnico ao uso dos números em questão. Para exemplificarmos esse caso, recorremos ao professor Paulos, que conta o seguinte caso bem humorado de uso técnico dos números:

O matemático G.H. Hardy foi visitar o seu protegido - o matemático indiano Ramanujan - ao hospital. À falta de melhor assunto, resolve observar que mil setecentos e vinte e nove, o número do táxi que o trouxera ao hospital, era um número deveras aborrecido. Ramanujan 
replicou imediatamente: "Não, Hardy, não! É um número interessantíssimo! É o número mais pequeno com que se pode exprimir, de duas maneiras diferentes, a soma de dois cubos (PAULOS, 1988, p.17).

Já uma dona de casa, ao seguir suas receitas, verá nos números tão somente a porção exata dos ingredientes. Um velocista, ao contrário, dá aos números o sentido altamente preciso, que escapa às pessoas comuns. É comum atribuir-se um sentido obscuro ao uso do código numérico, ideológico, por exemplo, na explicação de um "pacote econômico". A versatilidade do sentido empregado ao código numérico, pela universalidade da linguagem numérica, estendida que está a todas as atividades humanas, pensamos que é ilimitada. Por isso, defendemos a idéia de que a apropriação do sentido de uso do número significa também apreensão das relações humanas que configuraram tal uso. Dominar a aplicação do código numérico, neste sentido, é poder adequar a representação numérica, socialmente aceita às mais variadas dimensões da vida humana. E esta possibilidade se torna viável quando consideramos o número como uma forma de linguagem e não apenas como um recurso lógico-matemático, pois o número é muito mais do que isso; é, sobretudo, uma linguagem explicativa da realidade, que é, acima de tudo, multifacetada, ou como disse Marx, síntese de múltiplas determinações. Poderíamos dizer que a realidade humana atual é uma realidade prenhe de números e a sua utilização, em muitos momentos, chega a se confundir com outras formas de linguagens, como a alfabética, a dos sinais de trânsito, a musical etc. Nas linguagens esotéricas, inclusive, o número, via de regra, é um elemento fundamental, e isso não acontece apenas na numerologia. Então, é bem possível que um esotérico atribua aos números um sentido especial, num dado momento, e no seguinte, viram apenas elementos contábeis. Conclui-se daí que o sentido de uso do código numérico vai depender das relações sociais em que está inserido e da possibilidade de expressão matemática de tal contexto, tendo em vista os objetivos dos interlocutores envolvidos. 
Sendo o número fundamento da linguagem matemática, a partir da modernidade, a educação matemática deve considerar este conteúdo como sua própria espinha dorsal e voltar-se para o seu ensino, levando em conta que não se trata apenas de um conteúdo técnico e específico, mas se trata de uma forma específica de linguagem, cuja internalização por parte dos educandos é fundamental para que possam se apropriar do próprio modo de viver dos homens do nosso tempo, um modo de viver cada vez mais expresso numericamente.

\section{Referências bibliográficas}

BERNAL, J. D.. Ciência na história. Lisboa: Livros Horizontes, 1975.

BRINGUIER, J.. Conversando com Piaget. Rio de Janeiro/São Paulo: DIFEL, 1978.

MARX, K.. Manuscritos econômicos e filosóficos. Rio de Janeiro: Zahar, 1979.

1984.

A ideologia alemã. Teses sobre Feuerbach. São Paulo: Moraes, O capital. São Paulo: DIFEL, 1985.

PAULOS, J. A.. Inumerismo: o analfabetismo matemático e suas conseqüências. Portugal: Europa-América, 1988.

PIAGET, J.. Para onde vai a educação? Rio de Janeiro: José Olympio, 1978.

. Psicologia da inteligência. Rio de Janeiro: Zahar, 1983.

VENTURA, L.. Apropriação e conceito de número numa perspectiva histórica. 1999. $101 \mathrm{f}$. Dissertação (Mestrado) - Universidade do Estado de Santa Catarina, Florianópolis, 1999. 


\section{Autor:}

Lidnei Ventura

Professor colaborador do Centro de Educação a Distância (CEAD) da Universidade do Estado de Santa Catarina (UDESC), na disciplina de Didática. Trabalhou com Didática da Matemática, no curso de Pedagogia da Universidade do Vale do Itajaí. Orientador Educacional da Rede Municipal de Ensino de Florianópolis desde 1994.

Contato: $\underline{\text { lirventura@ig.com.br }}$

Artigo recebido em maio de 2009.

Artigo aprovado para publicação em julho de 2009.

\section{Como citar este texto:}

VENTURA, L.. Considerações sobre a apropriação do número e da linguagem numérica. Revista Acolhendo a Alfabetização nos Países de Língua Portuguesa, Brasil, São Paulo, volume 1, no. 10, pp. 69 - 87, Mar. 2011. Disponível em: 〈http://www.acoalfaplp.net>. 